Научная статья

УДК 94(470.6) + 316.4

DOI: $10.17213 / 2075-2067-2021-5-44-52$

\title{
ПОСЕЛЕНЧЕСКИЙ УКЛАД КАК СОЦИАЛЬНЫЙ ИНСТИТУТ (НА ПРИМЕРЕ ИСТОРИЧЕСКОГО РЕГИОНА КУБАНИ)
}

\author{
Александр Павлович Скорик \\ Южно-Российский государственный политехнический университет (НПИ) \\ имени М. И. Платова, Новочеркасск, Россия \\ s_a_p@mail.ru, ORCID: 0000-0003-1283-8137, AuthorID РИНЦ: 437141
}

Аннотация. Цель - определение параметров и индикаторов ключевого сочииального института поселенческого уклада в рамках историко-пространственной концепции Cossack world of the Kuban.

Методология иеленаправленно фундируется социогуманитарным ичивилизационным подходом и объясняет генерализующий поселенческий алгоритм закрепления казачества на новых российских территориях, определяемых как исторический регион Кубани.

Результаты исследования заключаются в формировании историко-пространственной концепции Cossack world of the Kuban, где социальный институт поселенческого уклада является базисным основанием.

Перспективы исследования заключаются в развитии теорий среднего уровня и введения их в теоретико-методологическое пространство при исследовании регионального научного дискурса.

Ключевые слова: идентичность, казаки, концепџия, Кубань, поселенческий уклад, станица, фронтир, хутор

Для цитирования: Скорик А. П. Поселенческий уклад как сочииальный институт (на примере исторического региона Кубани) // Вестник Южно-Российского государственного технического университета. Серия: Социально-экономические науки. 2021. T. 14, №5. C. 44-52. http://dx.doi.org/10.17213/2075-2067-2021-5-44-52.

Original article

\section{SETTLEMENT LAYOUT AS A SOCIAL INSTITUTE (ON THE EXAMPLE OF THE HISTORICAL REGION OF KUBAN)}

\author{
Aleksandr P. Skorik \\ Platov South Russian State Polytechnic University (NPI), Novocherkassk, Russia \\ s_a_p@mail.ru, ORCID: 0000-0003-1283-8137, AuthorID RSCI: 437141
}

Abstract. The purpose of the study is to determine the parameters and indicators of the key social institution of the settlement structure within the framework of the historical and spatial concept of the Cossack world of the Kuban.

(C) Скорик А.П., 2021 
The methodological basis of the study is purposefully based on the socio-humanitarian civilizational approach and explains the generalizing settlement algorithm for the consolidation of the Cossacks in the new Russian territories, defined as the historical region of the Kuban.

The results of the study. Formation of the historical and spatial concept of the Cossack world of the Kuban, where the social institution of the settlement structure is the basic foundation.

The prospects of the study. Are in the development of middle-level theories and their introduction into the theoretical and methodological space in the study of regional scientific discourse.

Keywords: identity, Cossacks, concept, Kuban, settlement way, village, frontier, farm

For citation: Skorik A. P. Settlement layout as a social institute (on the example of the historical region of Kuban) // Bulletin of the South Russian State Technical University. Series: Socio-economic Sciences. 2021; 14 (5): 44-52. (In Russ.). http://dx.doi.org/10.17213/2075-2067-2021-5-44-52.

Введение. Формирование казачьих поселений на Кубани является тем ключевым звеном научного поиска, которое позволяет выявить все смежные звенья исторической цепи событий и проследить коллизионный путь заселения, освоения и развития несколько большей территории, нежели нынешний Краснодарский край, ибо понятие исторического региона Кубани заметно шире. Главное - что в этом сложном историческом процессе зарождается региональный поселенческий уклад кубанских казаков, а его предназначение в повседневной жизни казачества имеет многофункциональный характер, его существование получает многолетнюю перспективу, его развитие приобретает многовекторную направленность, его содержание по определению отличается многоплановостью, его воздействие носит мультипликативный эффект. Тем самым поселенческий уклад выступает для Кубани традиционным автохтонным социальным институтом, во многом заимствованным у запорожцев и донцов, уникальной формой самоорганизации жизнедеятельности казаков, формирующей колоссальный историко-культурный потенциал территории Кубани. В итоге рождается историко-пространственная концепция Cossack world of the Kuban («казачий мир Кубани»), приверженцами которой мы выступаем.

Южнорусский фронтир и поселения. Первые российские поселенческие образования начали возникать на Кубани как в местах расположения крепостей, редутов, иных военных укреплений, так и на берегах больших рек и многочисленных речушек. Освоение новых российских территорий осуществлялось в массе своей служилым населением - казачеством, особым российским сословием, которое, помимо выполнения функций охраны южных рубежей страны, осваивало премудрости нелёгкого земледельческого труда на новых землях. Первые казачьи поселения выполняли в регионе охранительную функцию и выступали фронтиром для южных рубежей Российской империи. По мнению Ю. А. Мизиса, О.В. Скобелкина и А.И. Папкова, «фронтир является районом колонизации, присоединённая территория заселяется выходцами с основной территории государства, и новое население ведёт активную экономическую деятельность по освоению присоединённой территории» $[6$, с. 8]. Тем самым фронтир трактуется как зона экономического, социального, политического и культурного взаимодействия пришлого, нового населения с коренным населением. В то же время некоторые учёные считают, что нельзя сводить историю пограничья к осуществлению колонизации, поскольку в создании фронтира, кроме переселенцев, принимает участие и местное коренное население. Можно согласиться с Томасом Барреттом (применившим теорию фронтира по отношению к терским казакам [10]), который правомерно утверждал, что по-настоящему понять историю южнорусского фронтира, «понять подлинное присоединение Кавказа к России можно, заглянув лишь за военные линии, обратившись к взаимоотношениям и передвижениям людских потоков, шедших через Северный Кавказ, причём не только во время войны, но и во время мира, в повседневности» $[1$, c. 163$]$.

Из многих типов зарождающихся поселений - слободка, заимка, курень, хутор, 
зимовник, кош - основными поселенческими образованиями стали сформированные казаками станица (курень) и хутор. Этот базисный стержень поселенческой структуры складывался в ходе интенсивного заселения и хозяйственного облагораживания южнороссийских, кубанских земель в конце XVIII и на протяжении XIX вв. Под воздействием целого ряда факторов имперскими властями и войсковыми структурами осуществлялось социальное конструирование военно-организационной, этнокультурной и хозяйственно-земледельческой идентичностей, что позиционировало казачьи поселения в историческом пространстве как уникальное естественно-историческое явление, презюмировало тот самый казачий мир в южно-российском историческом регионе Кубани в имперский период российской истории.

Ключевые дефиниции поселенческого уклада. Среди изученных нами поселенческих структур кубанского казачества, составляющих социальный институт поселенческого уклада, наибольшее значение имеют два типа поселений: станица и хутор. Поэтому данное обстоятельство налагает на нас обязанность сформулировать авторское понимание двух ключевых дефиниций хронотопически предопределённого поселенческого уклада.

Как мы полагаем, казачий хутор - это социально-экономическая и поселенческая структура, отличающаяся способами ведения хозяйственной деятельности и организации системы землепользования, наличием территориального общественного самоуправления (обусловленного местными традициями), обустройством повседневного быта и архетипичными чертами культуры хуторян, ноосферным формированием эколого-природной среды обитания, преимущественными моделями экономического поведения и характерной ментальностью жителей [7].

Станица, с нашей точки зрения, это постоянное казачье поселение, являющееся административным центром для территориально установленного станичного юрта с земельными угодьями и иными населёнными пунктами, объединявшее самодеятельное казачье общество со своим самоуправлением, выступавшее базой для формирования воин- ского подразделения, сохранявшее самобытный казачий поселенческий уклад.

И всё же исторически первым типом поселения в историческом регионе Кубани являлись не хутора и станицы, а слободки, о чём свидетельствуют изученные нами историографические факты [4; 9].

Казачья слободка - это, по нашему мнению, исторический тип поселения, имеющий временный характер по периоду своего существования, занимающий по масштабам земельной площади небольшой участок, связанный с освоением новых российских земель как опорный посёлок, стимулируемый к своему появлению освобождением переселенцев от государственных и иных податей, образуемый, прежде всего, вольным казачьим населением, организующим повседневную деятельность на принципах традиционного самоуправления. Итак, получается всего семь признаков, семь индикаторов в понимании изначального исторического типа поселений, использовавшегося казаками при освоении новых российских территорий в историческом регионе Кубани. Тем самым казачья слободка являет собой тактическое средство маркирования осваиваемого пространства новых российских земель, выступает корпоративной практикой апроприации территории Черномории (Черноморского казачьего войска). Речь идёт об изначальной форме поселенческого уклада как социального института.

Подчеркнём, изучение поселенческих образований является неотъемлемой частью концептуалированной истории, той её обширной, актуальной и в значительной мере междисциплинарной части, которую сегодня называют everyday studies («исследования повседневности»), поскольку возникновение поселенческих образований на Кубани по определению детерминировано совокупностью факторов - геополитических, социальноэкономических, этнодемографических, культурных, естественно-географических. Так соединились изначально мощный кавказский вектор российской геополитики, «горячая полоса» северокавказского (южнорусского) фронтира, социально-экономическая необходимость создания дополнительных для страны продовольственных ресурсов, этнодемографическая потребность укрепления славян- 
ского ядра на Северном Кавказе, культурантропологическая целесообразность консолидации переселенцев на Кубани, естественногеографическое разнообразие осваиваемых территорий северо-восточного Причерноморья и районов Прикубанья. В обозначенных условиях воздействия совокупности факторов складывался «социальный капитал» и образ кубанской станицы. Приведём лишь две из множества весьма симптоматичных оценок этого ключевого образования для поселенческого уклада кубанского казачества.

Находясь на Кубани в 1919 г., один из вождей белого движения П.Н. Врангель, штаб соединения которого располагался в станице Темиргоевской (ныне станица в Курганинском районе Краснодарского края), отмечал следующее: «Стоял прекрасный осенний день. По сторонам дороги тянулись недавно убранные поля, бесконечные бахчи с зелёными арбузами и золотистыми дынями, обсыпанные плодами фруктовые сады. Громадные станицы с каменными, покрытыми черепицей зданиями, паровыми мельницами, широкими площадями с белыми златоглавыми храмами посреди - всё говорило о богатстве края» [2, с. 15].

В свою очередь, советский писатель, журналист и литературный функционер В.П. Ставский, характеризуя одну из кубанских станиц, поэтично размышлял: «Если глядеть из-за Кубани - хищной птицей сѐла на кручи станица, нахмурила зелёные заросли бровей. Вдоль тугой луки правого берега на добрый десяток вёрст раздалась станица Вальяновская (имелась в виду станица Васюринская (aвm.), ныне станица в Динском районе Краснодарского края) - ни с какой деревней, ни с каким селом не сравнимая Кубанская станица» [8, с. 7].

Многогранность поселенческого уклада. Наличествующие ныне социально-экономические, аграрно-политические и культурные характеристики отдельных кубанских поселений можно существенно дополнить, заметно расширить и показать их в качестве живого организма в исторически конкретной динамике с учётом особенностей образа жизни казачества, иногородних (городовиков) и иных категорий населения. Важно также подчеркнуть роль и место казачьих поселений в процессе хозяйственного освоения территории кубанского края как самодостаточного исторического явления, как неотъемлемой части общероссийской земледельческой культуры, выступающей в процессе исторического познания когнитивно-дискурсивной универсалией аграрного производства. Полифункциональность казачьих поселений выявляется в результате обстоятельного исследовательского изучения, как с точки зрения внутренних особенностей этого социального образования, так и с позиций процессов политической, социальной и аграрной эволюции южно-российской деревни, ведь исторический регион Кубани формировался как перспективный источник наращивания земледельческого потенциала Российской империи, он и сегодня является мощным центром аграрного производства Российской Федерации.

Кубань - это край с богатой самобытной казачьей историей, представляющий собой синтез локальных традиций при наличии непременной связи с общероссийскими тенденциями исторического развития, а изучение регионального опыта позволяет лучше понять российскую историческую идентичность. В свою очередь, региональная историческая идентичность заключается в том числе в поселенческом укладе, институализация которого у нас не вызывает сомнений ввиду вышеизложенных социальных индикаторов. Тем не менее, несмотря на наличие богатого исторического опыта, многое сегодня оказалось уже подзабытым и/или безвозвратно утраченным (разработанные практики регулирования миграционных потоков, управления значительными движущимися людскими массами, технологии обеспечения локальной безопасности и т.д.). Поэтому изучение процесса формирования поселенческих структур Кубани, выявления генерализующих характеристик поселенческого уклада представляет собой неотъемлемую часть migration studies («миграционных исследований»), образующих в настоящее время обширное междисциплинарное направление, и эти штудии совершенно очевидно страдают от дефицита ретроспективного изучения миграционных процессов, особенно в привязке к современному социокультурному и политическому контексту, с недавних пор сделавшему тему миграций крайне актуальной. 
Кубанские казачьи поселения в рамках понятийного научного дискурса представляют собой многогранное историческое явление. Здесь надо обратить первостепенное внимание на следующие сюжетные линии при истолковании обозначенной дефиниции региональных поселенческих структур. Вопервых, казачьи поселения (курень, станица, хутор) исторически зарождались и длительное время функционировали на Кубани в качестве поселенческого военизированного образования, призванного, прежде всего, обеспечивать повседневную безопасность жизнедеятельности его жителей.

Во-вторых, казачьи поселения изначально складывались на территории Кубани как целостная хозяйственно-культурная система, а экономическая эффективность её работы во многом предопределялась той исторической эпохой, в пределах которой казачьи поселения существовали. Кубанские поселения и поныне позиционируют поистине уникальный казачий культурно-хозяйственный уклад, демонстрирующий имманентные характеристики казачьей общности.

В-третьих, развитие казачьих поселений детерминируется установленным порядком землепользования и правом собственности на землю, регулируемыми действующим российским и региональным законодательством, причём при известном правовом нигилизме земельных собственников местные законы на Кубани всегда исполнялись лучше, нежели общероссийские.

В-четвёртых, казачьи поселения являются неотъемлемой частью наличествующей региональной земледельческой культуры (агрикультуры) южно-российской деревни, когда казаки с немалым личным удовлетворением называют себя хлеборобами, то есть людьми, знающими истинный толк в хлебопашеском труде.

В-пятых, кубанские поселения были и остаются носителем определённого казачьего колорита поселенческой общности, которая представляет этносоциальное и демографическое лицо Кубани. В этой связи довольно остро стоит проблема «монетизации» этнокультурных традиций в целях восстановления и/или развития демографического и этнокультурного потенциала сельских территорий в регионе, равно как и целесообраз- ности глобального охвата этим современным трендом всех казачьих поселений.

В-шестых, локальный мир кубанского казачества в станицах и хуторах представляет собой традиционное общество, и его презюмирует характерная система межличностных отношений и социальных взаимодействий, составляющих социально-психологическую атмосферу казачьего поселения. Она отличается особой ментальностью и совокупностью общественных интересов, проявляющихся во всём многообразии, в зависимости от той исторической эпохи, в которой поселения существуют. И здесь учёный неизбежно становится на антропологические рельсы и попадает в сферу kinship studies («исследование родства»), причём, если для любого краеведа и широкой краеведческой аудитории это приобретает исключительно принципиальный характер, то для профессионального историка и социолога непременно надо изучить Kinship Circle («родственный круг»), но ровным образом лишь настолько, чтобы понять истинную сущность традиционного общества.

Исследовательские векторы поселенческого уклада. Обозначенная выше категориально-понятийная научная презентация кубанских казачьих поселений отражает ключевые моменты историко-пространственной концепции Cossack world of the Kuban («казачий мир Кубани»). Важно изучить исторический ресурс казачьих поселений в коммуникативных диапазонах материально-хозяйственных, военно-организационных, социокультурных и духовно-нравственных технологий кубанских казаков, образующих в процессе реализации поселенческий уклад в станицах и хуторах. В фокусе исследовательского внимания должна находиться устойчивость и изменчивость поселенческих структур, их историческая динамика, сочетание социальности и персональности в поселенческом укладе, соотношение традиций и новаций в организации жизненного пространства в местах жительства кубанских казаков, проекция типов поселений в региональном контексте на этапах заселения новых территорий, хозяйственного облагораживания и последующей поселенческой трансформации.

Процесс изучения казачьих поселенческих образований, во-первых, предполагает 
обращение к базисным характеристикам исторического региона Кубани, в пространственном контексте которого формировались и развивались казачьи поселенческие структуры, причём они одновременно несли на себе достаточно заметный отпечаток различных природно-географических условий приморской Черномории, равнинных районов Прикубанья, низменной дельты Кубани, предгорных и горных ландшафтов Закубанья.

Во-вторых, мы рассматриваем генезис кубанских казачьих поселений как регионального историко-культурного образования, отличающегося совокупностью имманентно присущих черт, позволяющих выделить и проследить на конкретно-исторических материалах функционирование целого ряда типов поселенческих структур на Кубани, хотя основными формами организации жизненного пространства кубанских казаков оставались станицы и хутора.

В-третьих, названные типы поселенческих структур на Кубани обладают не только значительной устойчивостью, но и немалой изменчивостью, динамика которой заметно нарастает на мере приближения к рубежу XIX и XX вв., поэтому требуется учитывать сразу несколько разнонаправленных исторических тенденций, или сценариев, хозяйственно-культурного позиционирования и коммуникативного взаимодействия.

В-четвёртых, поселенческое обустройство на территории Кубани демонстрирует уникальные социальные практики решения казаками различных материально-хозяйственных, архитектурно-строительных, миграционных, военно-организационных и нормативно-правовых проблем в процессе формирования, трансформации и утверждения казачьего поселенческого уклада. Одним из ключевых показателей благополучия кубанских поселений при этом выступает экономическая эффективность наличествующей хозяйственной системы, которая претерпела существенные исторические изменения. Залогом административно-территориальной устойчивости казачьих поселений на Кубани являлась нормативно-правовая регуляция, во многом подчинённая законам военного времени.

B-пятых, в коммуникативных диапазонах различных типов поселений и исторического региона Кубани в целом мы пытаемся понять взаимоотношения между разными группами переселенцев на Кубань, и, прежде всего, для нас особую актуальность приобретает социальная дискуссионная панель «казаки vs иногородние». Этим взаимоотношениям присущи глубина и многослойность, в них выражаются как глобальные, так и предельно частные, в том числе индивидуальные, мотивы и ракурсы. Инклюзивные группы в поселениях кубанских казаков (иногородние крестьяне, мещане и пр.) находились в неравном положении по сравнению с казаками, и наличествовавший диспаритет никак не устраивал неказачьи слои населения, возникал целый спектр конфликтного взаимодействия.

В-шестых, развитие казачьих поселенческих структур обременялось внутригрупповым социальным расслоением в среде самого кубанского казачества, и соответственно трансформировался комплекс реальных и нормативно закреплённых прав (привилегий) и обязанностей для зажиточного казачества и для беднейших слоёв казачества, коренные интересы которых нередко заметно отличались.

В-седьмых, эволюция кубанских казачьих поселений предопределяется культурноэтническим своеобразием самого кубанского казачества, сохранившего в повседневных практиках значимые пласты этнической культуры (традиционные верования и обрядность, социальные структуры, систему питания, навыки хозяйственной деятельности и т.д.). Однако интерпретация этого этнокультурного нарратива нами осуществляется в контексте исследовательского направления critical heritage studies («критические исследования наследия»).

Функциональность поселенческого уклада. Исторические поселения казачества являлись опорными центрами освоения новых территорий в историческом регионе Кубани, центрами цивилизационного влияния на окружающее их пространство и обладали характерной притягательностью для переселяемого сюда населения, поскольку в них казаки стремились закрепить историко-культурное своеобразие своего поселенческого уклада и самобытность самих поселений. Поселенческий уклад кубанских казаков вы- 
ступает для нас фундирующей исторической научной категорией. Поселенческий уклад предполагал использование казаками вполне определённой планировочной структуры поселения, парцелляцию земельных участков, ведение привычной для казаков застройки, возведение технологически отработанных типов жилищ, учёт ландшафта данной местности, а также иные, нематериальные характеристики казачьего поселения, существенно дополняющие его традиционный архитектурно-художественный колорит, и в совокупности своей указывающие на детерминирующие антропологические признаки данного типа поселения. Устойчивое развитие исторического поселения кубанского казачества предопределяется степенью соответствия времени и месту его возникновения, способностью адаптации исторического поселения к новым условиям, и здесь неизбежно применение факторного анализа с выявлением исходного импульса военного, экономического, социального и иного порядка, стимулировавшего рост и укрепление данного казачьего поселения на Кубани.

Исторические поселения казачества реализовывали, прежде всего, для местного населения целый ряд сервисных антропогенных функций, помимо возможности постройки жилья и обеспечения общественной безопасности. Речь идёт о видовом разнообразии хозяйственных занятий, организации производства продуктов питания, налаживании путей сообщения, административном управлении, образовательной деятельности, проведении общего досуга, консолидации населения близлежащих территорий, медицинском обслуживании, осуществлении товарообмена и простейших торговых операций, рекреационных возможностях, установлении почтово-телеграфной связи, гарантировании пожаротушения. Оптимальными типами исторических поселений кубанского казачества в плане выполнения обозначенных поселенческих сервисных функций оказались станица и хутор, хотя полного и однозначного вытеснения из социального пространства других типов исторических поселений казачества на Кубани не произошло, и они в той или иной степени встречаются на территории региона как факт социальной реальности или же как фрагмент исторической памяти казачьей общности, подтверждаемый изучением коммеморационных практик, длительное время продуцируемых самобытной казачьей культурой.

Исторические поселения «представляют единый территориальный комплекс культурного и природного наследия, признанный на основе объективных исследований имеющим значительную научную, эстетическую и мемориальную ценность» [5, с. 76], а, следовательно, мы изначально направляем вектор исследовательского внимания не только в историческое прошлое кубанского казачества, но и внимательно всматриваемся в наше зримое настоящее, когда непременно требуется сберечь доставшееся нам в благонаследие от прежних поколений уникальное культурно-историческое наследство в виде исторических поселений. Соответственно, очевиден просветительный историзм предлагаемой нами парадигмальной модели поселенческого уклада. Исторические поселения являют собой дискурсивные конструкции регионального пространства, возникающие из сложного переплетения политики и географии, власти и поселенческого уклада, отражающие социальные и политические иерархии, играющие существенную роль в формировании/конструировании казачьей идентичности.

Заключение. Поселенческий уклад кубанского казачества мы относим к разряду так называемых теорий среднего уровня, идея введения которых в теоретико-методологическое пространство гуманитарных наук принадлежит американскому социологу Роберту Мертону [3]. Предлагаемый авторский теоретический конструкт, с нашей точки зрения, позволяет на основе целенаправленного изучения и последовательного обобщения конкретно-исторического материала показать роль и определить значение казачьих поселенческих структур в региональном историческом процессе и в истории кубанского казачества. Тем самым можно осуществить непосредственную связь теоретико-методологических положений с реальной практикой возникновения и трансформации кубанских казачьих поселений, что и обеспечивает высокий качественный уровень предпринимаемых научных изысканий в отношении поселенческих струк- 
тур кубанского казачества. Концепт поселенческого уклада кубанского казачества вовсе не исключает применения иных теоретикометодологических конструкций для познания процесса возникновения и трансформации поселенческих структур в историческом регионе Кубани, которые следует рассматривать под разными углами зрения.

\section{Список источников}

1. Барретт Т.М. Линии неопределённости: северокавказский «фронтир» России // Американская русистика: вехи историографии последних лет. Императорский период. Самара: СГУ, 2000. С. 163-165.

2. Врангель П.Н. Воспоминания. Ноябрь 1918 - ноябрь 1920. Ч. 1. М.: Наука, 2011. $244 \mathrm{c}$.

3. Девятко И.Ф.Р. Мертон и его теория среднего уровня // История теоретической социологии в 4-х т. Т. 3 / Под ред. Ю.Н. Давыдова. М.: Наука, 1997. С. 250-270.

4. Короленко П.П. Первоначальное заселение черноморскими казаками Кубанской земли // Известия ОЛИКО (Общества любителей изучения Кубанской области). Вып. 1. Екатеринодар: ОЛИКО, 1899. 125 с.

5. Крогиус В.Р. Исторические города России как феномен её культурного наследия. М.: Прогресс-Традиция, 2009. 310 с.

6. Мизис Ю.А., Скобелкин О.В., Папков А.И. Русский фронтир: политические, социальные и экономические аспекты (юг России в XVI - конец XVIII в.) // Вестник Тамбовского университета. Сер. Гуманитарные науки. 2015. Вып. 10 (150). С. 7-15.

7. Скорик А.П., Федина И.М. Кубанский хутор: фазы и повседневность топохронной эволюции (конец XVIII - первая треть XX вв.). Новочеркасск: Лик, 2016. 419 с.

8. Ставский В.П. Станица. Кубанские очерки. М. - Л.: Знание, 1929. 126 с.

9. Фелицын Е.Д. Краткий очерк заселения Кубанской области // Известия Кавказского отдела Императорского Русского географического общества. Тифлис: ИРГО, 1884 1885. T. VIII. $244 \mathrm{c}$.

10. Barrett T. M. At the Edge of Empire: The Terek Cossacks and the North Caucasus Frontier. 1700-1860. Boulder; Oxford: Westview Press, 1999. 264 p.

\section{References}

1. Barrett T. M. Linii neopredeljonnosti: severokavkazskij «frontir» Rossii [Lines of uncertainty: the North Caucasian «frontier» of Russia]. Amerikanskaja rusistika: vehi istoriografii poslednih let. Imperatorskij period [American Russian studies: milestones of historiography of recent years. The imperial period]. Samara: SGU, 2000. 163-165. (In Russ.).

2. Vrangel' P.N. Vospominanija. Nojabr' 1918 - nojabr' 1920 [Memoirs. November 1918-November 1920]. Part 1. Moscow: Nauka, 2011. 244. (In Russ.).

3. Devjatko I. F.R. Merton i ego teorija srednego urovnja [R. Merton and his theory of the average level]. Istorija teoreticheskoj sociologii v 4-h t. T. 3 [The History of theoretical Sociology in 4 vol. Vol. 3]. Pod red. Ju. N. Davydova [In Yu. N. Davydov (eds.)]. Moscow: Nauka, 1997. 250-270. (In Russ.).

4. Korolenko P.P. Pervonachal'noe zaselenie chernomorskimi kazakami Kubanskoj zemli [The initial settlement of the Kuban land by the Black Sea Cossacks]. Izvestija OLIKO (Obshhestva ljubitelej izuchenija Kubanskoj oblasti) [News of SLSKR (Society of Lovers of studying the Kuban region)]. Ekaterinodar: OLIKO, 1899; 1:125. (In Russ.).

5. Krogius V.R. Istoricheskie goroda Rossii kak fenomen ejo kul'turnogo nasledija [Historical cities of Russia as a phenomenon of its cultural heritage]. Moscow: Progress-Tradicija, 2009. 310. (In Russ.).

6. Mizis Ju. A., Skobelkin O.V., Papkov A. I. Russkij frontir: politicheskie, social'nye i jekonomicheskie aspekty (Jug Rossii v XVI konec XVIII v.) [The Russian frontier: political, social and economic aspects (the South of Russia in the XVI - end of the XVIII century)]. Vestnik Tambovskogo universiteta. Ser. Gumanitarnye nauki [Bulletin of the Tambov University. Ser. Humanities]. 2015; 10 (150): 7-15. (In Russ.).

7. Skorik A. P., Fedina I. M. Kubanskij hutor: fazy i povsednevnost' topohronnoj jevoljucii (konec XVIII - pervaja tret' XX vv.) [Kuban farm: phases and everyday life of topochronous evolution (the end of the XVIII - the first third of the XX centuries)]. Novocherkassk: Lik, 2016. 419. (In Russ.). 
8. Stavskij V.P. Stanica. Kubanskie ocherki [The village. Kuban essays]. Moscow-Leningrad: Znanie, 1929. 126. (In Russ.).

9. Felicyn E. D. Kratkij ocherk zaselenija Kubanskoj oblasti [A brief outline of the settlement of the Kuban region]. Izvestija Kavkazskogo otdela Imperatorskogo Russkogo geograficheskogo obshhestva [News of the Cauca- sian Department of the Imperial Russian Geographical Society]. Tiflis: IRGO, 1884-1885; VIII: 244. (In Russ.).

10. Barrett T. M. At the Edge of Empire: The Terek Cossacks and the North Caucasus Frontier. 1700-1860. Boulder; Oxford: Westview Press, 1999. $264 \mathrm{p}$.

Статья поступила в редакиию 07.09.2021; одобрена после рецензирования 18.09.2021; принята к публикаиии 27.09.2021.

The article was submitted on 07.09.2021; approved after reviewing on 18.09.2021; accepted for publication on 27.09.2021.

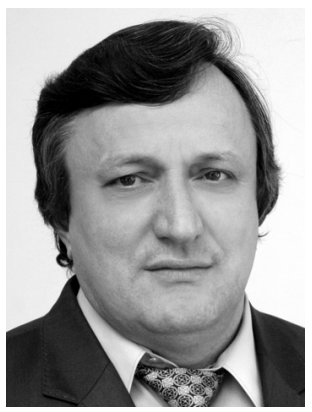

\section{ИНФОРМАЦИЯ ОБ АВТОРАХ}

Скорик Александр Павлович - доктор философских наук, доктор исторических наук, заслуженный работник Высшей школы Российской Федерации, профессор кафедры «Социальные и гуманитарные науки», Южно-Российский государственный политехнический университет (НПИ) имени М. И. Платова.

Россия, г. Новочеркасск, ул. Просвещения, 132

Aleksandr P. Skorik - Doctor of Philosophical Sciences, Doctor of Historical Sciences, Honored Worker of Higher School of the Russian Federation, Professor of the Department of Social Sciences and Humanities, Platov South Russian State Polytechnic University (NPI).

132 Prosveshcheniya st., Novocherkassk, Russia 